Ci. agríc., v. 1, n. 1, p. $7 \cdot 14,1991$

\title{
COMPARAÇÃO DE MÉTODOS DE DETERMINAÇÃO DA UMIDADE DO SOLO PARA FINS DE IRRIGAÇẨ (1)
}

\author{
CARLOS BRANCILDES MONTE CALHEIROS(2) \\ $\&$ \\ ELIZAGETH ARNDT(3)
}

\begin{abstract}
RESUMO
No sentido de definir um método prático, rápido, simples e preciso para determinação do grau de umidade de solos para fins de irrigação, foram comparados entre si os métodos gravimétrico padrão de secamento em estufa, 0 das pesagens e o do álcool. Foram usadas amostras de dois solos-Latossolo Vermelho Amarelo, textura franco-arenosa, e Latossolo Vermelho Escuro, textura argilosa - típicos do Município de Piracicaba-SP. Foi adotado o delineamento em blocos ao acaso, com parcelas subdivididas, tendo-se umidades na parcela e métodos na subparcela, repetidos quatro vezes. O teste de Tukey foi adotado para comparação dos valores médios dos graus de umidade obtidos pelos três métodos. Tais valores mostraram diferenças entre si. Estas diferenças foram mais acentuadas nos valores fornecidos pelo método do álcool. Não obstante os dados obtidos, o método das pesagens apresenta-se como bastante promissor no controle das irrigações, em substituição ao gravimétrico padrão de secamento em estufa.
\end{abstract}

Termos para indexação: umidade do solo, métodos, controle da irrigação.

(1) Trabalho aceito para publicaçåo em 19 de maio de 1991.

(2) Prof. Assistente, Departamento de Agronomia - CECA/UFAL. 57080 - Macelo, AL.

(3) Engenheira Agrícola, Especialista em Irrigaçăo e Drenagem. R. Lago Erié, Blc B-1, Apt-14, Residencial do Lago - 79069 - Campo Grande, MS. 


\section{ABSTRACT}

\section{COMPARATING OF METHODS OF THE DETERMINATION OF SOIL MOISTURE FOR IRRIGATIONS}

In order define a method prractice, rapid, simple and accuracy in the determination of soil moisture for irrigation ending, going to comparate oven-method, the wighage and burning alcohol methods. Was used samples of two soils - Yallow Red Latosol, sandy loam texture, and Dark-Red Latosol, clay texture, both Oxisols. Adopted a randomized blocks, with split-plot, repeated four time. The Tukey test was used for comparating of the means values of the moisture obtained. These values say diferences between hinselves. These diferences was largest in the values furnished by alcohol method. In spite off the data obtained, the weighage method presents as very promiser in irrigation control, in substitution of the oven-meethod drying.

Index terms: soil moisture, methods, irrigation control.

\section{INTRODUÇÃO}

A prática do cultivo irrigado, exige o conhecimento prévio do teor de água no solo como parâmetro básico para cálculo da lâmina de irrigação a ser aplicada. $O$ custo relativo da água destinada à irrigação é elevado. Ela deve, portanto, ser aplicada na quantidade mais próxima possível daquela que a planta necessita.

Considerando a magnitude da frequência de irrigação, o nível de instrução do nosso agricultor e o nível tecnológico de nossa agricultura, se faz necessário buscar um método rápido, de fácil execução (simples) e que possa ser utilizado em condições de campo (PAPADAKIS, 1941; KLAR et alii, 1966; BERNARDO, 1971).

$\mathrm{Na}$ busca de um procedimento adequado, que reunisse o máximo de vantagens possíveis, KLAR et alii (1966) e BERNARDO (1971) incorporaram sensiveis melhorias no método das pesagens, criado por PAPADAKIS (1941). Estes Autores concluiram que este método fornece resultados estatisticamente equivalentes àqueles produzidos pelo método gravimétrico padrão. Considerando isto e as vantagens práticas que o método possui, estes Autores recomendam-no para a determinação do grau de umidade de solos para fins de irrigação, en substituição ao gravimétrico padrão.

KELLEY et alii (1946) citam que uma das principais críticas ao método de secamento em estufa refere-se ao fato deste não considerar adquadamente o conceito da relação energia-umidade. 
KLAR $€$ t alii (966) detetaram diferenças significativas entre valores de umidade determinados por esse método, para um mesmo teor de água no solo.

Através de subsequentes queimas de porções de álcool em contato direto com a amostra do solo de interesse e consequente evaporação da água dessa amostra e da dissolvida no álcool, BOUYOUCOS (1928) idealizou o método do álcool para determinação da umidade de amostras de solo. Também EOUYOUCOS (1937) assegura ser o método do álcool tão preciso quanto o gravimétrica padrão, para solos minerais, tendo a grande vantagem de ser um método rápido. Nesses solos, teores de matéria orgânica até $11 \%$, segundo o autor, não são a fetados pela queima do álcool. Esse método pode determinar o teor de água de areias em 5 a 10 minutos, de solos francos em 10 a 20 minutos e de argilas em 10 a 35 minutos, a depender do teor de água neles contidos e da permeabilidade desses ao álcool.

Enfim, a comprovação de que um método qualquer de rápida determinação da umidade do solo seja, relativamente ao gravimétrico padrão de secamento em estufa, suficientemente preciso para que não provoque diferenças significativas nas alturas (individual e/ou total) de água de irrigação, traria enormes benefícios à prática da agricultura irrigada, principalmente em condições de projeto, na medida que fosse rápido, de fácil execução e de baixo custo.

\section{MATERIAL E MÉTODOS}

O experimento foi desenvolvido no Laboratório de Física e Mecânica de Solos do Departamento de Engenharia Rural da ESALQ/USP, no período de março a maio de 1987. Foram ctilizados os seguintes métodos: gravimétrico padrão de secamento em estufa (ABNT, 1989), das pesagens (PAPADAKIS, 1941; KLAR et alii, 1966; BERNARDO, 1971) e do álcool (BOLYYOUCOS, 1928 e 1937).

Para efeito de comparação dos métodos entre si, foram utilizadas amustras de dois solos do Município de Piracicaba-SP; Latossolo Vermelho Amarelo (LV), Série "Sertãozinho", tex tura franco arenosa e Latossolo Vermelho Escuro (LE), Série "Luiz de Queiroz", de textura argilosa.

As amostras desses solos foram tomadas na camada de 0 a $20 \mathrm{~cm}$ de profundidade e preparadas de forma convencional (secamento ao ar, destorroamento e tamizamento em malha de $2 \mathrm{~mm}$ de abertura).

Para a variação dos graus de umidade, optou-se por estabelecer um gradiente destes nas amostras, a partir do grau de umidade da TFSA. Assim, foram determinedcs os teores de água das TFSA's das duas amostras de solos (2,69\% para o LV e $14,74 \%$ para 
o LE) e tomadas várias amostras, de $1100 \mathrm{~g}$ cada, dos solos de interesse, sendo estas acondicionadas em recipientes (latas) de aluminio.

A estes recipientes foram adicionadas quantidades de água (medidas em $\mathrm{ril}$ ), em valores sempre crescentes e acréscimcs constantes, até próximo à saturação (verificada por inferência visual). Após isto, as amostras foram isoladas (fechadas ermeticamente) e mantidas assim ddurante 10 dias. Todos os dias fazia-se a açitação das amostras dentro dos recipientes, na tentativa de assegurar unra distribuiçãc uniforme da umidade em toda a amostra.

Após os 10 cilas iniciaram-se as determinaçōes dos graus de umidade, torrando-se 4 (quatro) subamostras de cada recipiente. Estas subamustras compunham as repetições do experimento.

Os dados obtidos foram submetidos a enálises estatísticas clássicas, a partir do delineamento $\epsilon \mathrm{m}$ bloccs ao acaso com parcelas subdivididas e fazendo a ccmparação dos valores médios dos graus de umidade através do teste de Tukey. Os graus de umidade (U) constituírar as percelas $\epsilon$ os métodcs $(M)$ as subparcelas.

\section{RESULTADOS E DISCUSSÃO}

Ocorreram variações significativas nos valores dos graus de umidade entre si, entre os métodos empregados. Isto é verificado pelos resultados do Quadro 1 e dos testes de F e de Tukey (Quadros $2,3)$. Os métodos estudados diferiram entre si na determinação da umidade do solo pelo teste de Tukey a $5 \%$ de probabilidade (Quadro 3).

O LV, como se previa, reteve menor quantidade de água ao longo da amostra nos recipientes, quando do estabelecimento dos diferentes graus de umidade. Para algumas amostras, portanto, certamente aquelas que receberam maiores quantidades de água, houve percolação e, como não havia possibilidade de drenagem do excesso, a água se acumulou na parte inferior do recepiente (fundo da lata). Isto deve ter induzido valores de graus de umidade nas subamostras consideravelmente discrepantes, afetando a precisão do ensaio (GOMES, 1985). No LE este efeito praticamente não se verificou; a textura deste solo proporcionou melhor distribuição da água na amostra, conferindo uniformidade nos valores dos graus de umidade das subamostras e elevando a precisão do ensaio (Quadro 2).

Independente do método adotado, os valores dos graus de umidade obtidos para o LV mostraram, na maioria dos casos, uma tendéncia de aumento no sentido correspondente ao da tomada de subamostras no recipientes, ou seja, da parte superior (tampa) para a inferior (fundo).

Os valores obtidos, usando o método do álcool, mostraram maiores discrepâncias, tanto em relação ao dessecamento em estufa 
QUADRO 1 - Valores médios dos graus de umidade em função dos métodos, para ambos os solos.

\begin{tabular}{|c|c|c|c|}
\hline $\begin{array}{l}\text { Pontos de } \\
\text { Umidade }\end{array}$ & Métodos & $\operatorname{LV}(1)$ & LE (2) \\
\hline 1 & $\begin{array}{l}E \\
P \\
A\end{array}$ & $\begin{array}{l}0,91 \\
1,32 \\
3,63\end{array}$ & $\begin{array}{l}2,61 \\
3,58 \\
8,00\end{array}$ \\
\hline 2 & $\begin{array}{l}E \\
P \\
A\end{array}$ & $\begin{array}{l}2,09 \\
1,65 \\
4,77\end{array}$ & $\begin{array}{r}7,90 \\
10,06 \\
12,42\end{array}$ \\
\hline 3 & $\begin{array}{l}E \\
P \\
A\end{array}$ & $\begin{array}{l}3,41 \\
3,20 \\
6,47\end{array}$ & $\begin{array}{l}12,46 \\
15,21 \\
17,65\end{array}$ \\
\hline 4 & $\begin{array}{l}E \\
P \\
A\end{array}$ & $\begin{array}{l}4,72 \\
2,79 \\
7,94\end{array}$ & $\begin{array}{l}15,48 \\
18,05 \\
21,59\end{array}$ \\
\hline 5 & $\begin{array}{l}E \\
P \\
A\end{array}$ & $\begin{array}{l}6,14 \\
4,93 \\
8,37\end{array}$ & $\begin{array}{l}17,80 \\
20,80 \\
21,99\end{array}$ \\
\hline 6 & $\begin{array}{l}E \\
P \\
A\end{array}$ & $\begin{array}{r}6,96 \\
5,38 \\
10,62\end{array}$ & $\begin{array}{l}21,72 \\
21,60 \\
24,65\end{array}$ \\
\hline 7 & $\begin{array}{l}E \\
P \\
A\end{array}$ & $\begin{array}{r}8,38 \\
6,80 \\
11,84\end{array}$ & $\begin{array}{l}24,17 \\
24,51 \\
28,59\end{array}$ \\
\hline 8 & $\begin{array}{l}E \\
P \\
A\end{array}$ & $\begin{array}{r}10,32 \\
7,12 \\
10,24\end{array}$ & $\begin{array}{l}26,57 \\
26,38 \\
30,95\end{array}$ \\
\hline 9 & $\begin{array}{l}E \\
P \\
A\end{array}$ & $\begin{array}{r}10,99 \\
8,74 \\
13,91\end{array}$ & $\begin{array}{l}- \\
-\end{array}$ \\
\hline 10 & $\begin{array}{l}E \\
P \\
A\end{array}$ & $\begin{array}{l}12,31 \\
11,31 \\
15,25\end{array}$ & $\begin{array}{l}- \\
-\end{array}$ \\
\hline
\end{tabular}

$E$ : método de secamento em estufa; $P$ : método das pesagens; A: método do álcool.

(1) Latossolo Vermelho Amarelo; (2) Latossolo Vermelho Escuro. 
QUADRO 2 - Análise de variância para valores médios dos graus de umidade e tipos de solo.

\begin{tabular}{|c|c|c|c|}
\hline \multirow{2}{*}{ Causa de variação } & \multirow{2}{*}{$\mathrm{GL}$} & \multicolumn{2}{|c|}{ QMR } \\
\hline & & LV & LE \\
\hline Blocos & 3 & 4,1418 & 0,7228 \\
\hline Umidade (U) & 9 & $154,6487^{* *}$ & $741,2582^{* *}$ \\
\hline Resíduo (a) & 27 & 0,6562 & 0,5212 \\
\hline (Parcelas) & (39) & & \\
\hline Métodos (M) & 2 & $164,8240^{* *}$ & $180,6967^{\star \star}$ \\
\hline Interação (UXM) & 18 & $2,2519^{* *}$ & $2,7076^{* *}$ \\
\hline Resíduo (b) & 60 & 0,8009 & 0,8720 \\
\hline \multirow[t]{4}{*}{ Total } & 119 & & \\
\hline & & - & \\
\hline & $C V(a)$ & 11,44 & 3,99 \\
\hline & $C V(b)$ & 12,63 & 5,16 \\
\hline
\end{tabular}

Significativo ao nível de $1 \%$ de probabilidade

QUADRO 3 - Resultados do teste de Tukey a $5 \%$ para graus de umidade e métodos, em ambos os solos.

\begin{tabular}{|c|c|c|}
\hline Pontos de Umidade & LV & LE \\
\hline $\begin{array}{r}10 \\
9 \\
8 \\
7 \\
6 \\
5 \\
4 \\
3 \\
2 \\
1\end{array}$ & $\begin{array}{r}12,96 \mathrm{a} \\
11,21 \mathrm{~b} \\
4,23 \mathrm{c} \\
9,00 \mathrm{c} \\
7,65 \mathrm{~d} \\
6,48 \mathrm{e} \\
5,15 \mathrm{f} \\
4,37 \mathrm{f} \\
2,87 \mathrm{~g} \\
1,97 \mathrm{~g}\end{array}$ & $\begin{array}{c}- \\
- \\
27,97 \mathrm{a} \\
25,76 \mathrm{~b} \\
22,65 \mathrm{c} \\
20,20 \mathrm{~d} \\
18,37 \mathrm{e} \\
15,10 \mathrm{f} \\
10,13 \mathrm{~g} \\
4,73 \mathrm{~h}\end{array}$ \\
\hline \multicolumn{3}{|l|}{ Métodos } \\
\hline $\begin{array}{l}\text { Álcool } \\
\text { Estufa } \\
\text { Pesagens }\end{array}$ & $\begin{array}{l}9,30 \mathrm{a} \\
6,62 \mathrm{~b} \\
5,32 \mathrm{c}\end{array}$ & $\begin{array}{l}20,73 \mathrm{a} \\
17,52 \mathrm{~b} \\
16,09 \mathrm{c}\end{array}$ \\
\hline
\end{tabular}

LV - Latossolo Vermelho Amarelo

LE - Latossolo Vermelho Escuro 
quanto entre os próprios valores referentes a um mesmo grau de umidade (repetições). De uma maneira geral, os valores médios obtidos por este método, de secamento em estufa, para qualquer grau de umidade considerado, diferenciando-se dos resultados obtidos por BOUYOUCOS (1937).

O tipo de material usado, grau de combustibilidade do álcool, cápsulas, suporte de cápsulas, etc., pode ter reduzido a eficiência de extração e evaporação da água contida na mistura solo+água, à medida que reduzia a quantidade de calor produzido na queima do álcool. A permeabilidade da amostra não se constituiu problema, pois além da textura ser franco arenosa (RANZANI et alii, 1966), a espessura da amostra na cápsula era pequena.

Uma outra possivel fonte de erro está no aquecimento da balança de pesagem. À medida que se procedia às sucessivas queimas e pesagens das amostras, a balança ia absorvendo certa quantidade de calor transferida pelo conjunto cápsula+suporte, aquecido pelo calor produzido nas queimas. A acumulação de calor pela balança pode ter alcançado uma magnitude tal que viesse a interferir na sensibilidade desta e provocado leituras erróneas.

O método das pesagens possibilitou valores de graus de umidade bem mais próximos daqueles fornecidos pelo de secamento em estufa, chegando, em vários casos, a valores idênticos, principalmente no LE e para graus de umidade mais altos. No LV ocorreram algumas variações entre os valores de graus de umidade nas subamostras e, de uma maneira geral, foram mais afastados dos fornecidos pelo secamento em estufa, quando comparadas com às no LE. Estas diferenças certamente são consequências da permanência de ar nos vazios das subamostras, principalmente no LE (PAPADAKIS, 1941). A agitação manual comumente recomendada, parece ter sido pouco eficiente. $O$ efeito disto é bastante relevante quando se sabe que o valor de M(KLAR et alii, 1966 e BERRNARDO, 1971), definido como constante na determinação do grau de umidade de amostras de solo pelo método das pesagens, sofre influência desta quantidade de ar nos vazios da amostra.

Entretanto, apesar dos resultados aqui obtidos, o método das pesagens pode se constituir num substituto eficiente e preciso do método de secamento em estufa, no controle da aplicação de água de irrigação. KLAR et alii (1966) e BERNARDO (1971) chegaram à mesma conclusão. Em virtude da extrema variabilidade dos solos e dos intensos distúrbios a que são frequentemente submetidos pelas práticas agrícolas, é aconselhável que o valor de $\mathrm{M}$, como um fator (constante para todas as determinações, dentro de um mesmo lote de amostras), seja determinado para cada situação particular e, mesmo assim, submetido a verificações periódicas.

Os resultados fornecidos pelo método padrão de secamento em estufa, foram mais uniformes para o LE, entre repetições de um mesmo grau de umidade. No LV, e em alguns casos, houve 
algumas discrepâncias entre os valores das subamostras para um mesmo grau de umidade, como afirmado por KLAR et alii (1966), exceto para valores de umidade mais baixos.

A magnitude das diferenças nos valores dos graus de umidade, relativamente aos obtidos pelo método de secamento em estufa, certamente interfere com a economicidade da irrigação, na medida que pode provocar excesso ou escassez de água no solo. Isto alcança proporções consideráveis se considerarmos que 0 efeito é cumulativo com as irrigações.

\section{LITERATURA CITADA}

ASSOCIAÇÃO BRASILEIRA DE NORMAS TÉCNICAS. Procedimento de ensaio para determinação do grau de umidade de solos. Rio de Janeiro: 1989 . NBR 69/1989.

BERNARDO, S. Determinação da umidade do solo pelo "método das pesagens". Rev. Ceres, Viçosa, v. 18, n. 15, p. 75-82, 1971.

BOUYOUCOS, G.J.. Determining soil moisture rapidly and accurately by methyl alcohol. J. Am Soc. Agron., v. 20, n. 1, p. 82-3, 1928. (Notes).

. Evaporating the water with burning alcohol as a rapid means of determining moisture content of soil. Soil Sci., Baltimore, $n$. 44, p. 377-381, 1937.

GOMES, F. P.. Curso de estatística experimental. Piracicaba: E.S. A. "Luiz de Queiroz". Nobel, 1985. 466p.

KELLEY,O.J., MUNTER,A.S., HAISE,H.R. \& HOBBS,C.H.. A comparison of methods of measuring soil moisture under field conditions. J. Am. Soc. Agron., v.38, n.9, p. 759-783, 1946.

KLAR,A.E., VILLA NOVA,N.A., MARCOS,Z.Z. \& CERVELLINI, A.. Determinação da umidade do solo pelo método das pesagens. Anais da E.S.A. "Luiz de Queiroz", Piracicaba, v.23, p. 15-30, 1966.

PAPADAKIS,J.S.. A rapid method for determining soil moisture. Soil Sci., Baltimore, v. 51, p. 279-281, 1941.

RANZANI,G., FREIRE,O., KINJO,T.. Carta de solos do Município de Piracicaba. Piracicaba: Centro de estudos de solos. E.S.A. "Luiz de Queiroz". 1966. 